\title{
A FABRICAÇÃO DO DISPOSITIVO DA EDUCAÇÃO INTEGRAL NA ORDEM DO DISCURSO DA EDUCAÇÃO BRASILEIRA
}

\author{
Rodrigo Milhomem de Moura* \\ Alexandre Ferreira da Costa**
}

\begin{abstract}
RESUMO: Neste trabalho, discutimos o processo de fabricação do dispositivo da educação integral (DEI) na ordem do discurso da educação brasileira, a partir de três momentos históricos: a EI em Anísio Teixeira, a EI em Darcy Ribeiro e o Programa Mais Educação. Em seguida, analisamos alguns dispositivos que sustentam o DEI na teia discursiva de nosso tempo: Plano de Nacional de Educação, Diretrizes Curriculares Nacionais e o dispositivo pedagógico da mídia. A linha teórica adotada no trabalho é a perspectiva da Análise de Discurso com filiação em Michel Foucault, a qual discute temas como discurso, poder/saber/verdade, que são elementos que permeiam e constituem um dispositivo (FOUCAULT, 1979, 1995, 2002a, 2003, 2008, 2014). Adotamos a pesquisa qualitativa, bibliográfica e documental no estudo (DENZIN e LINCOLN, 2006; GIL, 2002, SEVERINO, 2007). A partir de nossas análises, inferimos que a educação integral fez ecos em vários momentos de nossa história, respondendo a certas urgências históricas e assumindo estratégias diferentes em cada um desses momentos. Além disso, por ter se tornado um dispositivo de controle, busca capturar as subjetividades e controlar os sujeitos e as infâncias marginalizadas.
\end{abstract}

ABSTRACT: In this paper, I discuss the process of fabrication of the integral education apparatus (DEI) in the order of discourse of Brazilian education, from three historical moments: EI in Anísio Teixeira, EI in Darcy Ribeiro and the Mais Educação Program. Next, I analyze some devices that sustain the DEI in the discursive network of our time. The theoretical line adopted in the work is the perspective of Discourse Analysis with affiliation in Michel Foucault, which discusses themes such as discourse, can/know/ truth, which are elements that permeate and constitute a device (FOUCAULT, 1979, 1995, 2002a, 2003, 2008, 2014). I adopt qualitative, bibliographic and documentary research in the study (DENZIN e LINCOLN, 2006; GIL, 2002, SEVERINO, 2007). From our analyses, we infer that integral education has echoed at various moments in our history, responding to certain historical urgencies and assuming different strategies at each of these moments. Moreover, because it has become a device of control, it seeks to capture subjectivities and control marginalized subjects and childhoods.

PALAVRAS-CHAVE: Educação Integral. Análise de Discurso. Dispositivo.

KEYWORDS: Integral Education. Discourse Analysis. Apparatus.

\section{CONSIDERAÇÕES INICIAIS}

Os enunciados sobre Educação Integral (doravante EI) fazem parte do imaginário da sociedade brasileira há muitas décadas, e são marcados por rupturas, inovações e diferentes estratégias. Vários estudiosos como Anísio Teixeira e Darcy Ribeiro debruçaram-se sobre a temática no século XX, constituindo diversas políticas públicas para que ela pudesse ser inscrita na ordem discursiva de nossa sociedade. Mais recentemente, no início dos anos 2000, tornou-se foco das campanhas político-partidárias das mais variadas esferas (municipal, estadual e federal). Nos anos de 2007 e 2008, foi instituído o Programa Mais Educação (PME) do Governo Federal, que apresentou vistas INTERLETRAS, ISSN No 1807-1597. V. 9, Edição número 34. Outubro, 2021/ Março de 2022- p

Dossiê: Educação, infância, diversidade e ensino de língua em contexto complexo. 
a implementação da EI em âmbito nacional. O projeto foi bem recebido pelos governantes e passou a fazer parte da realidade de muitas escolas públicas do país.

Neste contexto, ressaltamos que a Educação Integral de nosso tempo sofre gradativas mudanças se comparada a proposta inicial de Anísio Teixeira e dos demais escolanovistas. Isso porque, novos enunciados foram emergindo sobre ela, dentre eles, expressões descritivas com diferentes conotações e valores: educação de tempo integral e educação integral de tempo integral. Moura (2020), discute que essas nomenclaturas são faces de um mesmo dispositivo, que se adaptou às épocas e englobou novos discursos, dizeres, saberes, poderes e verdades em seu escopo. Portanto, Educação Integral, Educação de Tempo Integral e Educação Integral de Tempo Integral correspondem a um mesmo dispositivo e assim, como Moura (2020), chamamos de dispositivo da educação integral (DEI) ou dispositivo da integralidade (DI). Ressaltamos que essas mudanças nos enunciados da Educação Integral ocorrem porque o dispositivo busca diversos modos para se manter na teia discursiva.

Esses enunciados não são neutros, mas interpelados por estratégias, discursos, relações de poder, saber e verdade (FOUCAULT, 1979, 1995, 2002a, 2003, 2008, 2014), que têm o intuito de "fazer dizer" e "fazer ver"; controlar e tornar produtivos os sujeitos que são interpelados por essas relações no âmbito do ensino de tempo integral. Afirmamos isso porque na perspectiva foucaultiana, um dispositivo discursivo engloba vários discursos, proposições, leis; é preenchido pelos regimes de verdade, permeado pelas relações de poder e saber, e visa controlar e ceifar a capacidade de resistência dos sujeitos (se rearranjando e englobando novas estratégias no decorrer das épocas). Outro ponto de destaque, é que esse mecanismo de controle necessita de outros dispositivos para se sustentar na teia discursiva (FOUCAULT, 2002a). É, pois, nesse sentido que defendemos que a EI é um dispositivo educacional de controle social, que passa a englobar em seu escopo: o tempo, o espaço, políticas públicas, leis etc., visando capturar os corpos e as subjetividades dos sujeitos educandos/as e dos/as profissionais que atuam nessa modalidade educacional.

Salientamos ainda que as discussões e reflexões sobre educação integral (como um dispositivo) surgiram a partir de nossas vivências no Programa Mais Educação e no Projeto Novo Futuro, que rege a Educação Integral de Tempo Integral de Goiás. Numa primeira visada, tivemos bastante dificuldade em reconhecer (e defender) que a EI poderia ter se tornando um dispositivo educacional, uma vez que essa modalidade surge apenas como um enunciado, um discurso no Brasil (considerando o contexto histórico-social ao qual ela se vincula) (MOURA, 2020). Desse modo, foi primordial buscar sua historicidade, a quais urgências históricas ela respondia e como se deu seu processo de fabricação em nossa sociedade. Tais problematizações, aliadas às nossas vivências, possibilitaram que esse trabalho fosse desenhado e escrito.

No âmbito dessas problematizações, questionamo-nos diversas vezes sobre dizeres e discursos que permeiam (ou permeavam) a EI e, assim, surgiram como inquietações: como o dispositivo da Educação Integral (DEI) foi engendrado na ordem do discurso da INTERLETRAS, ISSN No 1807-1597. V. 9, Edição número 34. Outubro, 2021/ Março de 2022- p

Dossiê: Educação, infância, diversidade e ensino de língua em contexto complexo. 
educação brasileira e quais dispositivos podem sustentá-lo na rede discursiva? Para tanto, objetivamos: a) discutir o processo de fabricação do dispositivo da educação integral (EI) na ordem do discurso da educação brasileira, a partir de três momentos históricos: a EI em Anísio Teixeira, a EI em Darcy Ribeiro e o Programa Mais Educação; e b) analisar alguns dispositivos que sustentam o DEI na rede discursiva de nosso tempo. Desse modo, realizamos uma pesquisa de cunho bibliográfico, documental e qualitativo. Bibliográfico e documental porque usamos artigos, livros, dissertações, teses, sites e documentos diretrizes, parâmetros, planos etc. (GIL, 2002; SEVERINO, 2007), para compreender e problematizar o tema. Qualitativo porque temos a possibilidade de analisar fenômenos específicos e construir interpretações sobre o nosso objeto de estudo, uma vez que "as interpretações qualitativas são construídas; não existe uma única verdade interpretativa, [...] o que existe são múltiplas comunidades interpretativas, cada qual com seus próprios critérios para avaliar uma interpretação" (DENZIN e LINCOLN, 2006, p. 37).

Reconhecendo esses aspectos, selecionamos como corpus de análise: as Diretrizes Curriculares Nacionais (2013), o Plano Nacional de Educação (2014-2024) e duas manchetes sobre educação integral: "cortes de vagas no ensino integral; e ensino Integral melhora índices de alunos no ensino superior", retiradas da Folha de São Paulo e do G1.com. Os dois veículos de comunicação social são de grande alcance e contribuem para formar a opinião de seus públicos. Além disso, essas duas manchetes fazem parte do corpus de análise de Moura (2020) e decidimos discuti-las, neste texto, por termos a oportunidade de aprofundar alguns elementos que não estavam nos objetivos do autor naquele momento. Por conseguinte, defendemos, no texto, que os documentos oficiais atuam como dispositivos de sustentação do DEI, pois visam regulamentar, fundamentar e nortear os paradigmas educacionais de nossa sociedade. Defendemos também que a mídia funciona como dispositivo pedagógico (FISCHER, 2000), visto que, intenta dar visibilidades, reproduzir enunciados e educar a população para a importância do dispositivo da educação integral.

Diante disso, a pesquisa tem sua singularidade por considerar a fabricação de um dispositivo educacional - o da integralidade/da Educação Integral -, e por demonstrar sua interdependência na teia discursiva com tantos outros dispositivos. Tais aspectos, por vezes, passam despercebidos pelos sujeitos que são interpelados por esses mecanismos (dispositivos) de controle. Ter noção de que eles existem pode ser importante para que professores/as, estudantes e muitas famílias possam criar novas formas de resistências às relações de poder/saber/verdade estabelecidas no interior desse mecanismo. Inclusive, lutando por condições educacionais melhores (em todos os âmbitos) e mais dignas para seus/suas filhos/as.

\section{ALGUMAS CONSIDERAÇÕES SOBRE OS ESTUDOS FOUCAULTIANOS}

Para refletirmos sobre discurso na perspectiva foucaultiana, devemos ter em mente o questionamento que o autor fez em sua obra metodológica A arqueologia do saber: o que possibilitou o surgimento de um enunciado e não outro em seu lugar? Pois, dessa forma,

INTERLETRAS, ISSN $N^{o}$ 1807-1597. V. 9, Edição número 34. Outubro, 2021/ Março de 2022- p

Dossiê: Educação, infância, diversidade e ensino de língua em contexto complexo. 
poderemos observar o caráter histórico e social do discurso, para, então, compreendê-lo como prática:

[...] o discurso não é uma estreita superfície de contato, ou de confronto, entre uma realidade e uma língua, o intrincamento entre um léxico e uma experiência; gostaria de mostrar, por meio de exemplos precisos, que, analisando os próprios discursos, vemos se desfazerem os laços aparentemente tão fortes entre as palavras e as coisas, e destacar-se um conjunto de regras, próprias da prática discursiva. (...) não mais tratar os discursos como conjunto de signos (elementos significantes que remetem a conteúdos ou a representações), mas como práticas que formam sistematicamente os objetos de que falam. (FOUCAULT, 2008, p. 56).

Dessa maneira, o que faz com dado discurso surja e não outro em seu lugar são as construções histórico-sociais, econômicas e discursivas de uma dada época. Assim, ao conceber o discurso como prática e não apenas como conjunto de signos, o autor reconhece as inúmeras e complexas relações sociais as quais os sujeitos estão submergidos. Sem perder de vista que esses sujeitos são interpelados pela história, pelos saberes, verdades e relações de poder, que os des/re/constituem dia após dia. Esses sujeitos fazem parte de uma sociedade, são, pois, "produtos" discursivos dela, e respondem às emergências históricas de sua época.

Nesta linha de debate, é válido ressaltar que a obra Michel Foucault costuma ser dividida por diversos autores em três períodos/domínios. Prado Filho et. al (2006) elucida essa ideia, descrevendo-a como Ser-saber, Ser-poder e Ser-consigo. De acordo o autor (2006, p. 04), o primeiro domínio é o da arqueologia (ser- saber), e está ligado ao saber. Neste momento, os discursos são tratados como práticas, "por seus efeitos de verdade, e na sua exterioridade, descentrado de representações, significados e sentidos, buscando expor suas condições históricas de possibilidade e emergência". Em outras palavras, torna-se necessário reconhecer o saber não como algo pré-dado, mas como "o conjunto dos elementos (objetos, tipos de formulações, conceitos e escolhas teóricas)" (FOUCAULT, 1995, p. 723), constituído histórica e socialmente por meio das relações de poder.

O segundo domínio (ser-poder) denominado de genealogia liga-se ao poder. Nesse momento, Foucault problematiza os biopoderes modernos: "disciplinas e biopolíticas, os dispositivos, a objetivação dos corpos, jogos de poder operando como microfísica" (PRADO FILHO et al, 2006, p.04). O poder passa a ser compreendido como algo que "só funciona em cadeia. Nunca está localizado aqui ou ali, nunca está nas mãos de alguns, nunca é apropriado como uma riqueza ou um bem. O poder funciona e se exerce em rede [...] o poder transita pelos indivíduos, não se aplica a eles" (FOUCAULT, 2010, p. 26). Ele circula e é exercido em várias circunstâncias, em vários locais e pelos sujeitos. É exercido nas relações sociais, que podem ser macro ou micro relações.

Em outras palavras, cada sujeito pode exercer o poder, seja um micropoder ou macropoder, a depender da posição-sujeito que ocupa. Reconhecer isso, é inferir que o poder é produtivo, e "atravessa todo o corpo social muito mais do que uma instância negativa que tem por função reprimir” (FOUCAULT, 2002a, p.9). Sob essa ótica, o poder

INTERLETRAS, ISSN $N^{o}$ 1807-1597. V. 9, Edição número 34. Outubro, 2021/ Março de 2022- p

Dossiê: Educação, infância, diversidade e ensino de língua em contexto complexo. 
não deve ser encarado apenas como algo negativo, de repressão, mas como produtivo, que produz saber, verdade, subjetivação e objetivação. As relações de poder transformam os sujeitos e a própria sociedade, vinculando-se às várias épocas. E onde há relações de poder, há possibilidades de resistência. E essa resistência, para Foucault (1979, p.241), deve ser tão inventiva e móvel quanto o poder:

Para resistir, é preciso que a resistência seja como o poder. Tão inventiva, tão móvel, tão produtiva quanto ele. [...] A partir do momento em que há uma relação de poder, há uma possibilidade de resistência. Jamais somos aprisionados pelo poder: podemos sempre modificar sua dominação em condições determinadas e segundo uma estratégia precisa.

A possibilidade de resistência faz com que o poder não nos aprisione, pois, diante de uma relação de poder, temos possibilidades de criar resistências, por meio de estratégias precisas, inventivas e criativas. Isso só é possível porque somos sujeitos livres. No âmbito educacional, por exemplo, em meio a tantos dispositivos, a capacidade de resistência faz com que os sujeitos professores/as, estudantes e até mesmo sociedade em geral questionem ou corroborem o sistema, os dizeres educacionais e algumas estratégias (as mais visíveis) dos dispositivos educacionais, inclusive o da integralidade/DEI. A partir disso, passam a produzir verdades e saberes sobre si, sobre os outros, sobre sua profissão, sobre a educação dos/as filhos/as e sobre as próprias realidades criadas a partir desses mecanismos de controle.

Embora o dispositivo intente capturar as subjetividades desses sujeitos, tornando-as aptas ao consumo e a produtividade eles ainda resistem ou, pelo menos, tentam. Já no terceiro e último domínio, o da ética de si (ser-consigo), "Foucault "propôs e aplicou o método de análise e subjetivações, ou de relações do sujeito consigo mesmo, que compõem uma ética, um governo sobre si mesmo" (PRADO FILHO et al, 2006, p.4-5). Os sujeitos são levados a se tornarem sujeitos por meio dos processos de objetivação e subjetivação (FOUCAULT, 1995; PANIAGO, 2005; PARAGUASSÚ, 2017) e pelos regimes de verdade. Dito nas palavras de Foucault (2004, p. 236) são os "processos de subjetivação e de objetivação que fazem com que o sujeito possa se tornar, na qualidade de sujeito, objeto de conhecimento".

A verdade também assume papel importante nessa constituição, visto que permeada pelas relações de poder, ela torna-se parte integrante de cada época, acolhendo determinados discursos e fazendo-os funcionar como verdadeiros ou falsos (FOUCAULT, 1979). A verdade, assim, não é pré-dada, mas construída em cada sociedade sob a égide das relações de poder/saber. $\mathrm{Na}$ educação, os/as professoras/es e alunos/as são confrontados/as com as verdades e saberes de seu tempo e por meio dos processos de objetivação e subjetivação que permeiam os dispositivos educacionais, constituem saberes sobre o "ser-professor/a" e sobre o ser "ser-estudante". Assim, historicamente, professores/as e estudantes subjetivam-se por meio das visibilidades da mídia, dos dizeres dos documentos oficiais, das representações do sujeito-professor/a, da relação com seus pares e com sua família e com a sociedade.

INTERLETRAS, ISSN $N^{\circ}$ 1807-1597. V. 9, Edição número 34. Outubro, 2021/ Março de 2022- p

Dossiê: Educação, infância, diversidade e ensino de língua em contexto complexo. 


\section{OS DISPOSITIVOS: CAMINHOS A DESBRAVAR}

Os dispositivos estão em todos os lugares e em todos os momentos de nossa vida, são preenchidos de estratégias e relações de poder/saber/verdade. Esse termo aparece na segunda época da obra do filósofo - a genealógica -, e é abordado em algumas circunstâncias sem que o autor disponibilize um conceito concreto para o termo. Por esse motivo, é considerado por alguns estudiosos como uma "amplitude" de outros conceitos já adotados por ele, como a noção de Formação Discursiva e a noção de Episteme, por exemplo. "Foucault explica que o que entende por "dispositivo é um caso muito mais geral de episteme' - que tem um caráter especificamente discursivo" (SARGENTINI, 2015, p. 21). Essa ideia expressa que um dispositivo engloba não só o discursivo como também o não discursivo, vários discursos, proposições filosóficas, formações discursivas, e é sempre interpelado pelas relações de poder/saber/verdade. Para Foucault (2002a, p. 244), o dispositivo deve ser entendido como:

[...] um conjunto decididamente heterogêneo que engloba discursos, instituições, organizações arquitetônicas, decisões regulamentares, leis, medidas administrativas, enunciados científicos, proposições filosóficas, morais, filantrópicas. Em suma, o dito e o não dito são os elementos do dispositivo. O dispositivo é a rede que se pode estabelecer entre estes elementos.

O dispositivo é, assim, uma rede que se estabelece com os ditos e também com os nãoditos, com os discursos, com as construções, leis etc., em diferentes circunstâncias, e esta rede é preenchida pelas relações de poder, saber e verdade. Todo dispositivo responde a uma emergência histórica, possui estratégias "mutantes" (que vão se reinventando no decorrer dos tempos) e buscam capturar, controlar, produzir dizeres, saberes e verdades nas complexas relações socioculturais. Em outras palavras, "um dispositivo é capaz de abarcar as complexas relações sociais nas quais se travam a luta entre poderes, saberes e verdades, a partir dos elementos heterogêneos que o constituem" (MOURA, 2020, p. 56). Para Foucault (2002a, p. 244), esses aspectos estão em relação, isto é, "entre estes elementos, discursivos ou não, existe um tipo de jogo, ou seja, mudanças de posição, modificações de funções, que também podem ser muito diferentes". Por meio dos dispositivos, no jogo estabelecido entre os elementos heterogêneos, os poderes e os saberes pode haver a invisibilização ou evidenciação de uma prática, a depender dos regimes de luz que recaem sobre ela, bem como das linhas de força que a confronta (DELEUZE, 2005).

Cada dispositivo está preenchido de estratégias mutantes que se adaptam aos tempos, épocas, saberes e verdades que são produzidos em cada sociedade. Essas estratégias têm o intuito de fazer com que o dispositivo permaneça "vivo" na rede discursiva. No próximo tópico, discutimos como o dispositivo da Educação Integral foi fabricado na ordem do discurso educação brasileira (EB).

INTERLETRAS, ISSN $N^{o}$ 1807-1597. V. 9, Edição número 34. Outubro, 2021/ Março de 2022- p

Dossiê: Educação, infância, diversidade e ensino de língua em contexto complexo. 


\section{A FABRICAÇÃO DO DEI NA ORDEM DO DISCURSO DA EDUCAÇÃO BRASILEIRA}

Discutimos a fabricação do dispositivo da educação integral a partir de Anísio Teixeira, Darcy Ribeiro e do Programa Mais Educação (2007/2008). Em Moura (2020), quando analisamos o processo de constituição do dispositivo da EI, percebemos que, no primeiro momento, essa modalidade de educação surgiu apenas como um enunciado/discurso, mas com o tempo foi englobando em seu escopo discursos, políticas, leis, (em)debates, construções, arquiteturas etc., até se tornar um dispositivo.

Anísio Teixeira foi responsável por diversas mudanças no cenário educacional baiano (e brasileiro). O sonho de uma educação pública de qualidade fez com que ele desenhasse currículos, políticas públicas e até mesmo empenhasse a construção de um grande complexo educacional (Carneiro Ribeiro). Desse modo, "a educação integral representava para Anísio Teixeira o modelo de solução para a realidade política e educacional brasileira, e todas as atividades que se realizavam no centro estavam permeadas por esse ideário" (TENÓRIO e SCHELBAUERI, 2014, p. 12). O Centro Educacional Carneiro Ribeiro contava com atividades educacionais diversificadas para os filhos e filhas das classes populares, que, muito frequentemente, passavam por diversos problemas sociais (pobreza extrema, fome...). Além disso, não tinham acesso à cultura e nem ao lazer. Mediante Moura (2020, p. 79), o acesso das crianças marginalizadas a uma escola pública "irá transformar a conjuntura histórica-social por completo e as curvas e as linhas do dispositivo da integralidade vão se evidenciando nas tramas discursivas da educação brasileira", tendo em vista que, em sua maioria, quem tinha acesso ao ensino era a elite da época.

O projeto educacional empenhado por Teixeira foi de grande valia para a construção do dispositivo da integralidade na ordem do discurso da educação brasileira (fazendo ecos ainda hoje). Assim, ao reconhecermos esse percurso e pensarmos com Veyne (2014, p. 57) que "o dispositivo mistura, [...] vivamente, coisas e ideias (entre as quais a verdade), representações, doutrinas, e até mesmo filosofias, com instituições, práticas sociais, econômicas etc.", entenderemos as condições que possibilitaram esse dispositivo se instaurar na paisagem educacional brasileira.

A emergência histórica desse dispositivo surgiu, portanto, em um momento de lutas e resistências travadas por diversos educadores/as (em especial, os escolanovistas), contrários ao sistema dominante, que excluía os menos favorecidos. Dessa forma, o DI permeado pelas relações de poder, saber e verdade, preenchido de estratégias mutantes (que o farão permanecer na teia discursiva) passou a fazer parte do imaginário educacional brasileiro. É válido ressaltar que o projeto de Anísio foi encerrado por outras relações de poder que se instalaram na ordem do discurso daquele período, que levaram ao fracasso a proposta de EI daquele momento (mas o dispositivo da educação integral, já instituído permaneceu "vivo" na rede discursiva).

Mais adiante em nossa história, o DEI apresentou-se a partir de novas vozes sociais, emergindo com nova força e novas estratégias. Darcy Ribeiro, no governo de Leonel INTERLETRAS, ISSN No 1807-1597. V. 9, Edição número 34. Outubro, 2021/ Março de 2022- p

Dossiê: Educação, infância, diversidade e ensino de língua em contexto complexo. 
Brizola, empenha um projeto de educação integral. A emergência histórica do dispositivo será, então, o analfabetismo, que apresentava índices alarmantes: "uma empreitada importante para justificar a necessidade de uma educação que formasse o indivíduo em sua integralidade e o tirasse da vulnerabilidade social" (MOURA, 2020, p. 81).

Assim, Darcy Ribeiro elabora várias políticas públicas voltadas para a EI: formação de professores, criação de eventos pedagógicos, além de empenhar a construção dos Centros Integrados de Educação Pública (CIEP). E, conforme discutimos em Moura (2020, p. 83) "o processo de implantação dos Ciep ocasiona fortes modificações não só na estrutura das relações na escola - físicas e interpessoais -, mas na estrutura social”, ou seja, a sociedade passa a produzir dizeres e a constituir verdades sobre a arquitetura e sobre a formação educacional das crianças pobres/marginalizadas.

Mesmo diante de tantas possibilidades para a educação pública brasileira, quando Brizola saiu do poder e Darcy Ribeiro não conseguiu se eleger governador do Rio de Janeiro, o projeto de educação integral mais uma vez foi frustrado e adiado. Contudo, é válido salientar que um dispositivo se rearranja às épocas, englobando em seu escopo novas estratégias e discursos. O DEI nunca foi destruído, pois fez-se presente em várias instituições brasileiras, ressurgindo com grande força em 2007/2008 com o Programa Mais Educação do Governo Federal (PME).

A partir do referido Programa, começou-se a pensar sobre o tempo integral na educação (agora em âmbito nacional). O programa foi bem recebido pelos representantes da grande maioria dos estados e municípios, e logo começou a ser implementado em várias escolas públicas do Brasil (sem o preparo físico e humano necessário). Com o PME, instalou-se nos currículos das escolas um período semi-integral. O qual previa aula em turno regular com as disciplinas do núcleo obrigatório (português, matemática, história etc.) e, no contraturno, os alunos deveriam ter acesso à cultura, à arte, ao esporte, ao lazer e às complementações pedagógicas, por meio de oficinas.

O dispositivo da EI ressurge preenchido de novos discursos, respondendo a novas demandas históricas e preenchido de diversas estratégias, com vistas a capturar as subjetividades dos sujeitos e torná-los aptos ao consumo e à produtividade. Para Santaiana (2015, p. 44), o dispositivo da educação integral "pode ser visto como algo que se dispõe em inúmeras práticas, por meio de estratégias específicas que se vinculam a outras tantas, em uma rede de poder e saber, sustentando discursos e instituindo verdades". Esse mecanismo de controle produz novas formas de encarar a EI, agregando a ela novos dizeres, saberes, verdades e poderes, com vistas a capturar e retirar dos sujeitos a capacidade de resistência. Em outras palavras,

Na educação de tempo integral, o tempo se torna disciplinador e, por isso, os corpos estão sujeitos nos dois turnos de aula às inspeções, ao controle e à racionalidade econômica da vida - à capacidade de ser produtivo. Nesse processo, sendo a escola um lugar de (re)produção e de controle do discurso, observamos os conjuntos discursivos de elementos heterogêneos, permeados pelas relações de poder que interpelam esse espaço e os sujeitos "livres" que INTERLETRAS, ISSN N $N^{\circ}$ 1807-1597. V. 9, Edição número 34. Outubro, 2021/ Março de 2022- p

Dossiê: Educação, infância, diversidade e ensino de língua em contexto complexo. 
ali estão. O dispositivo da integralidade se dispersa no tempo e espaço, nos diversos discursos e práticas, sem se situar ou criar amarras em nenhum deles, todavia interpelando-os e capturando suas subjetividades. (MOURA, 2020, p. 91).

A tentativa de capturar as subjetividades e tornar as infâncias marginalizadas mais produtivas fará ecos em todo país, por meio do Programa Mais Educação. Uma das estratégias desse novo rearranjo de poder foi considerar a cidade como espaço educador. Além disso, as escolas passaram a ter autonomia para buscar parcerias e voluntários para fazer parte do grupo. Com o tempo, o dispositivo da integralidade mostrou-se ainda mais evidente, "a escola então se torna também um espaço de disputa e concorrência de inúmeros projetos, cada um com sua verdade e seus interesses, mas todos com um objetivo estratégico" (SANTAIANA, 2015, p. 55). Vários dizeres e discursos, mas pouca eficácia na maioria das escolas públicas brasileiras.

Todos esses processos são marcados pelo neoliberalismo, pela educação mercadológica e pela visão de uma escola-empresa, que prepara os indivíduos para agirem e atuarem no mercado, sendo produtivos (DARDOT e LAVAL, 2016). Este contexto neoliberal, no qual estamos inseridos, faz com que a inclusão do "tempo" nesta modalidade de educação torne-se uma forma de capacitar os sujeitos, tirando-os do contato com certas marginalizações sociais e tornando-os aptos a conhecer, aprender e desenvolver seu projeto de vida e seu "protagonismo". Palavra essa bastante neoliberal, que desconhece todos os riscos a que as infâncias marginalizadas são/estão submetidas. Logo, desconhece-se (ou se tenta desconhecer) que os mais pobres têm acesso a uma educação defasada na maioria das regiões (e instituições públicas) brasileiras.

Outros termos como "autonomia" e "projeto de vida", bastante presentes na educação integral, são excludentes e atendem aos anseios da ordem discursiva neoliberal, visto que os sujeitos educandos/as, subjetivados pelo sistema educacional, são levados a se tornarem empresários de si. Empresários que assumem para si todos os riscos, respondendo pelos seus erros e acertos; enquanto o Estado exime-se de sua responsabilidade. Afinal, o projeto de vida deve ser pensado e repensado para que o/a aluno/a consiga atingir seus objetivos, independentemente de suas dificuldades e limitações. Não concretizar esse projeto pode ser sinônimo de fracasso, não protagonismo e de não autonomia na escrita de sua própria história.

Feitas essas considerações, reafirmamos que o DEI não está sozinho nesse jogo de poder (de interesses) mas é sustentado por outros dispositivos - de controle, visibilidade e regulamentação da educação. Selecionamos para as análises as Diretrizes Curriculares Nacionais e o Plano Nacional de Educação, pois têm caráter instrucional, normativo e norteador da Educação brasileira; bem como à mídia, que veicula dizeres e visibilidades sobre a EI, que educam a população para o consumo, dá visibilidades a certos dizeres e verdades, e forma a opinião dos sujeitos para comprarem e acreditarem nessa proposta do dispositivo. Essa será a discussão levantada no próximo tópico. 


\section{DISPOSITIVOS QUE SUSTENTAM O DEI NA REDE DISCURSIVA}

O Plano Nacional de Educação - PNE (2014-2024) é uma ferramenta que prevê em dados, metas e datas o que deve ser feito no âmbito educacional. É refeito a cada dez anos e expressa em sua meta de número seis a necessidade de oferta da EI: "oferecer educação em tempo integral em, no mínimo, cinquenta por cento das escolas públicas, de forma a atender, pelo menos, vinte e cinco por cento dos (as) alunos(as) da educação básica" (BRASIL, 2014/2024, p. 59). Essa previsibilidade do documento, que coloca como necessidade a oferta de EI na educação básica, revela-nos que esse documento sustenta a necessidade de uma educação integral para o/a estudante de escola pública, colocando, inclusive, como uma meta a ser atingida para essa escola e não para a escola particular. Tais discursos, demonstram, no nosso entendimento, que, mais uma vez, os corpos que precisam ser formados "integralmente", ou melhor, controlados e capturados são os mais vulneráveis socialmente - os que estão nas instituições públicas - as infâncias marginalizadas.

A educação integral pensada para as instituições públicas de ensino e evidenciada no documento, apresenta vistas ao controle das subjetividades fragilizadas, para que elas se tornem produtivas na sociedade, tanto no âmbito do estudo quanto no âmbito do trabalho e consumo (no futuro). Assim, desse modo, poderão "devolver" ao Estado todo o investimento feito, já que para nos tornarmos um país "desenvolvido" necessitamos de bons resultados nos exames nacionais e internacionais, dentre outras medidas.

No que concerne às estratégias do documento para atingir a referida meta, vemos na seis ponto dois o caráter de assistência, de atendimento às crianças e adolescentes em situação de vulnerabilidade social, como instituir, em regime de colaboração o "programa de construção de escolas com padrão arquitetônico e de mobiliário adequado para atendimento em tempo integral, prioritariamente em comunidades pobres ou com crianças em situação de vulnerabilidade social" (p. 60). Contudo, a inclusão da EI na educação pública contou com pouquíssima mudança no mobiliário, o que se viu, na verdade, foram escolas sem estruturas físicas e pedagógicas adequadas (MOURA, 2020).

Desse modo, ao enunciar sobre as metas para a EI e ao expressar para quais públicos ela deverá ser implementada, confirmamos a tese de que o dispositivo da integralidade está a serviço de uma ordem muito mais ampla - um projeto neoliberal de Estado, que controla as infâncias marginalizadas, para que sejam produtivas socialmente. As Diretrizes Curriculares Nacionais também chamam a atenção para a importância da educação integral na escola pública ("local onde se encontram altos índices de vulnerabilidade social") e evidencia que:

[...] a proposta educativa da escola de tempo integral poderá contribuir significativamente para a melhoria da qualidade da educação e do rendimento escolar, ao passo em que se exorta os sistemas de ensino a ampliarem a sua oferta. Esse tipo de escola, quando voltada prioritariamente para o atendimento das populações com alto índice de vulnerabilidade social que, não por acaso, encontram- se concentradas em instituições com baixo rendimento dos alunos, situadas em capitais e regiões

INTERLETRAS, ISSN No 1807-1597. V. 9, Edição número 34. Outubro, 2021/ Março de 2022- p

Dossiê: Educação, infância, diversidade e ensino de língua em contexto complexo. 
metropolitanas densamente povoadas, poderá dirimir as desigualdades de acesso à educação, ao conhecimento e à cultura e melhorar o convívio social. (BRASIL, 2013, p. 124).

Os discursos evocados no documento dizem respeito à necessidade e à importância da EI para a população mais vulnerável. Os dizeres mobilizados no documento sustentam o DEI e, passam a subjetivar os indivíduos que estão envolvidos no processo educacional integral, que acabam constituindo e reconstituindo suas identidades. Isso ocorre, porque visa-se o controle e a produtividade dessas crianças e jovens, pois na lógica neoliberal eles se tornam consumidores e passam a dar "menos" prejuízos do que se estivessem nas ruas. Nesse sentido, Agamben (2009, p. 46) pondera que "os dispositivos visam, através de uma série de práticas e de discursos, de saberes e de exercícios, à criação de corpos dóceis, mas livres, que assumem a sua identidade e a sua "liberdade" de sujeitos do próprio assujeitamento".

Para o referido autor, o dispositivo busca criar corpos dóceis, além disso, defende que é uma máquina de produzir subjetivações, visto que produz e reproduz dizeres sobre o que é ser professor/a e aluno/a de educação integral, e sobre a importância dessa modalidade para a sociedade. Ressaltamos assim, que o excerto: "prioritariamente para o atendimento das populações com alto índice de vulnerabilidade social" demonstra o que vimos discutindo até aqui: as estratégias que nos são apresentadas sobre a EI fazem parte de um projeto muito maior de controle e captura do tempo, espaço e subjetividade dos sujeitos periféricos e marginalizados. As incoerências também se referem ao fato de acesso à cultura, esporte e lazer. Em Goiás, conforme constatamos em MOURA (2020) muitas escolas estaduais não têm o mínimo para o funcionamento integral, como por exemplo, um refeitório satisfatório, uma quadra de esportes adequada, lugares para os/as estudantes tomarem banho e/ou descansarem, entre tantos outros aspectos.

Em suma, os dois documentos/dispositivos reproduzem diversos discursos sobre a importância de manutenção da EI na teia discursiva, salientando o caráter assistencial às infâncias marginalizadas. Feita essa ponderação, vamos ao último dispositivo - a mídia - que também atua sustentando o dispositivo da EI na ordem do discurso da educação brasileira. Acreditamos que ela, enquanto dispositivo, educa a população para a necessidade e importância (ou não) da educação integral.

Ao postular sobre o dispositivo pedagógico da mídia, Fischer (2002, p. 156) demonstra que esse aparato é discursivo por produzir discursos, saberes e verdades, e "ao mesmo tempo não discursivo (uma vez que está em jogo nesse aparato uma complexa trama de práticas, de produzir, veicular e consumir TV [...] numa determinada sociedade e num certo cenário social e político)". Nas tramas discursivas, esse dispositivo sustenta dizeres, discursos e saberes sobre a EI e "tais práticas vêm acompanhadas de uma produção e veiculação de saberes sobre os próprios sujeitos e seus modos confessados e aprendidos de ser e estar na cultura em que vivem" (FISCHER, 2002, p. 156). Para demonstrar esse aspecto, selecionamos duas manchetes. Na primeira, os sujeitos veem-se na obrigação de

INTERLETRAS, ISSN $N^{\circ}$ 1807-1597. V. 9, Edição número 34. Outubro, 2021/ Março de 2022- p

Dossiê: Educação, infância, diversidade e ensino de língua em contexto complexo. 
cobrar mais vagas nas escolas que ofertam o tempo integral, em oposição ao corte de vagas feito pelo prefeito:

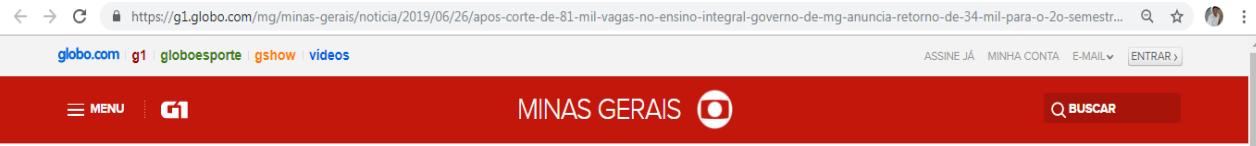

Figura 1:

Após corte de 81 mil vagas no ensino integral, Governo de MG anuncia retorno de 34 mil para 0

Cortes de $2^{\circ}$ semestre

vagas no

ensino

integral

De acordo com a Secretaria de Estado de Educação, a redução do programa foi necessária para regularizar a distribuição da merenda. Mais de 47 mil alunos devem ficar de fora até 2020.

Fonte:

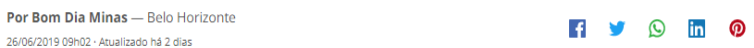

G1.globo.com

A partir de cobranças da Assembleia Legislativa - MG, que fiscaliza as ações do governo e atua na posição de representante do povo, percebemos na manchete, que o governador decidiu reverter os cortes. Essas visibilidades dadas pela mídia acabam educando a população para que cobrem seus direitos, e um deles é ter mais vagas nas escolas de tempo integral, para que a população menos favorecida economicamente possa ter um lugar onde deixar os/as filhos/as quando estão no trabalho. Lugar também onde essas famílias acreditam que seus/suas dependentes terão alimentação, já que em muitas casas as crianças e adolescentes passam necessidades básicas de alimentação.

Os dizeres de Moura (2020) vêm ao encontro dessa discussão. Em sua pesquisa de mestrado sobre educação integral, constatou a partir da análise de narrativas de seis professoras e de um professor que atuam em um centro de período integral de Goiás que muitos alunos/as vão à escola para se alimentar, e para terem um lugar onde ficar enquanto seus/suas responsáveis trabalham. Nesse sentido, atuando como um dispositivo pedagógico, a mídia sustenta o DEI na ordem discursiva, pois veicula dizeres sobre as cobranças pelas vagas na EI, concomitantemente, sobre a importância de manter esse dispositivo na sociedade. É válido dizer que "o dispositivo da mídia coloca em circulação as ações empreendidas na Educação Integral, mas, sobretudo consolida o exercício dos sujeitos de falarem sobre si, das boas práticas das instituições e escolas" (SANTAIANA, 2015, p. 165). Desse modo, esse aparato de poder torna-se uma máquina de fazer ver e dizer sobre educação integral, uma máquina de subjetivação, aspecto que podemos analisar na segunda manchete:

INTERLETRAS, ISSN No 1807-1597. V. 9, Edição número 34. Outubro, 2021/ Março de 2022- p

Dossiê: Educação, infância, diversidade e ensino de língua em contexto complexo. 


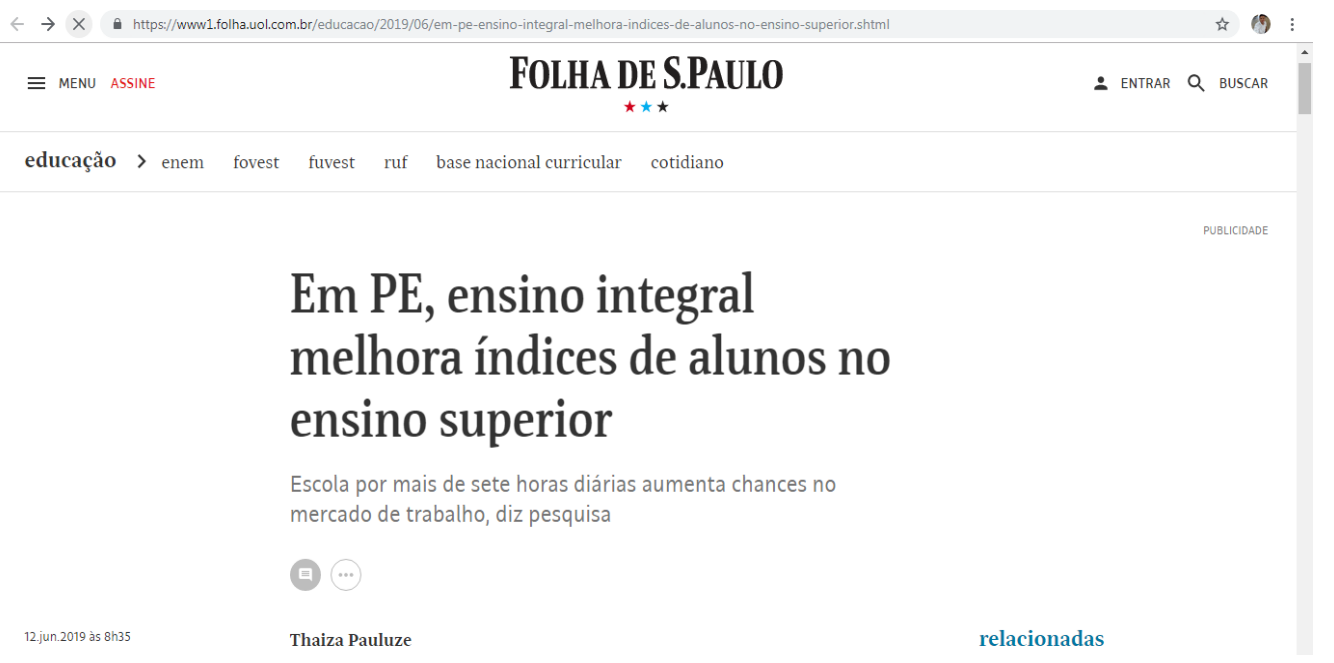

Figura 2: Ensino Integral melhora índices de alunos no ensino superior Fonte: Folha de São Paulo

A partir dessa manchete, podemos notar que outras possibilidades para que o DEI se mantenha na rede discursiva da educação brasileira são veiculadas pela mídia. No texto acima, evidencia-se a necessidade de mostrar os bons índices obtidos com a implementação dessa modalidade educacional e suas ramificações. Afinal, a educação integral pode dar certo, ("olhemos o caso de Pernambuco"). Esses discursos ecoam na sociedade e expressam que mais de $7 \mathrm{~h}$ de estudo podem ser importantes para galgar espaços no mercado de trabalho e no ensino superior. De acordo com Marcello (2004, p. 203) "a mídia, nessa perspectiva, não se ocupa apenas de emitir visibilidades, mas também, aliada ao processo incessante de repetição discursiva, ela justamente cria condições para a produção de novas discursividades". Discursividades essas que demonstram que se os/as estudantes estiverem estudando em uma escola de tempo integral terão mais chances de adentrar aos espaços universitários que, em sua grande maioria, lhes foram negados. O Brasil, historicamente, tem a tradição de excluir alunos/as de escolas públicas das universidades, principalmente, das públicas.

Dito de outro modo, esses dizeres sobre os/as estudantes que adentraram ao ensino superior, e possuem melhores "índices", inclusive, melhorando a qualidade dos cursos é uma forma de criar novas discursividades sobre o dispositivo da integralidade. Assim, adentrar a uma universidade pode significar sair da pobreza, e isso atrai a atenção das populações menos favorecidas. É uma possibilidade de ascensão social. Portanto, é uma forma de sustentar o dispositivo da integralidade (DEI), de modo que ele continue na rede discursiva, "produzindo" mais alunos que irão, por sua vez, possuir bons índices e, quem sabe, sonhar com o ensino superior. Além disso, é uma forma de capturar novas subjetividades e melhorar os índices nas avaliações regionais, estaduais, nacionais e internacionais. 


\section{CONSIDERAÇÕES FINAIS}

O trabalho objetivou demonstrar como o dispositivo da integralidade foi inscrito na ordem do discurso da Educação Brasileira e de como está relacionado na teia discursiva com outros dispositivos (documentos oficiais e mídia). Assim, observamos a partir do estudo e das análises que o dispositivo da educação integral começou a ser fabricado no Brasil com Anísio Teixeira, passando por Darcy Ribeiro até chegar ao PME. Cada um desses momentos foi preenchido de estratégias "mutantes" - que possibilitou ao DEI se adaptar e se rearranjar aos tempos e às épocas; também respondeu às emergências históricas de cada um dos períodos aos quais emergiu com mais força; sempre preenchido de relações de poder/saber/verdade que atuam na objetivação e subjetivação dos sujeitos, fazendo com que eles/as se des/re/constituam dia após dia. Contudo, é válido frisar, mais uma vez, que, diante de cada relação de poder, os sujeitos manifestam novas capacidades de resistência, pois, na visão foucaultiana são livres.

Reiteramos ainda que, os dispositivos não se mantêm na rede discursiva sem outros. No trabalho, citamos apenas a mídia, as Diretrizes Curriculares Nacionais e o Plano Nacional de Educação que funcionam como dispositivos que regulamentam, norteiam, dão visibilidade e sustentam o DEI na teia discursiva, mas há vários outros. Esses dispositivos, na esteira do controle, buscam tirar os indivíduos da marginalização social e dar-lhes um local para estudar em regime integral, com o objetivo de fazê-los atingir bons resultados nos exames e avaliações, tornando-os sujeitos aptos ao trabalho/produtividade e ao consumo. O dispositivo midiático dá a visibilidade necessária ao DEI e, assim, ajuda-o a se manter no jogo discursivo. E conforme expressam Assmann e Stassun (2010, p. 73) "o que está em jogo são as formas de se exercer o poder, apoiadas em instrumentos de saber, produzindo efeitos de subjetivação e sujeição". Dessa forma, para que um dispositivo surja é necessário que se sinta a necessidade de seu surgimento.

Dito de outro modo, uma necessidade constante. Por exemplo, para que os dispositivos de segurança surjam é necessário fabricar o medo: "a sensação de segurança e medo, a autonomia e de gerência das atitudes são exemplos dos efeitos duais de dispositivos de segurança na sociedade atual" (ASSMANN e STASSUN, 2010, p. 73). Assim, para que o dispositivo da integralidade se mantenha na rede discursiva, será necessário, além da sustentação dos outros dispositivos, continuar fabricando as infâncias marginalizadas. Algo que só será resolvido com o tempo integral. Mas, nem todos os/as estudantes serão convidados a entrar na ordem do dispositivo da educação integral (pública): entrarão nessa ordem àqueles/as que dela "necessitam" para se tornarem "protagonistas" e "autônomos" de sua própria história, em especial, os/as filhos/as da classe menos abastadas. Classes essas que precisam trabalhar para manter a engrenagem capitalista, concomitantemente, que necessitam de escolas de tempo integral ("com formação integral") para deixar seus/suas dependentes.

Portanto, no nosso entendimento, o dispositivo da EI evidencia a manutenção do capitalismo e neoliberalismo na rede discursiva. Isso não quer dizer que a educação integral seja ruim, "sem importância" e que visa apenas produzir corpos dóceis, mas, da forma que vem sendo apresentada à escola pública, intenta controlar e capturar as INTERLETRAS, ISSN No 1807-1597. V. 9, Edição número 34. Outubro, 2021/ Março de 2022- p

Dossiê: Educação, infância, diversidade e ensino de língua em contexto complexo. 
infâncias e adolescências mais fragilizadas, para que o sistema dominante continue ativo e "dominando". Por isso, reivindicamos, por meio deste texto, mais investimento na educação integral, para que ela possa colaborar com uma formação humana e crítica cada vez mais.

O trabalho deixa margens para que outras abordagens sejam realizadas acerca do dispositivo da integralidade. Por exemplo: como os instrumentos de avaliação, tanto nacionais (SAEB, ENEM, entre outros) quanto internacionais (Pisa) podem sustentar o dispositivo da integralidade? Os/as estudantes marginalizados não necessitam de qualidade para desenvolverem seu projeto de vida ou precisam de apenas uma escola de tempo integral? Por que não temos tantas escolas públicas e públicas-integrais com excelentes estruturas? O dispositivo estaria a serviço da manutenção dos privilégios da elite? Esperamos, assim, que o trabalho possa colaborar com futuras pesquisas e, que tais questionamentos, possibilitem o surgimento de outros estudos.

\section{REFERÊNCIAS}

AGAMBEN, GIORGIO. O que é o contemporâneo? E outros ensaios. (Tradução de Vinícius Nicastro Honesko). Chapecó: Argos, 2009.

ASSMANN, Selvino José. STASSUN, Cristian Caê Seemann. Dispositivo: Fusão de objeto e método de pesquisa em Michel Foucault. In: Caderno de Pesquisa Interdisciplinar em Ciências Humanas. Florianópolis, v.11, n.99, p. 71-92, jul/dez, 2010.

BRASIL. Lei no 13.005 , de 25 de junho de 2014. Aprova o Plano Nacional de EducaçãoPNE e dá outras providências. Diário Oficial da União, v. 26, 2014.

BRASIL. Ministério da Educação. Diretrizes Curriculares Nacionais Gerais da Educação Básica / Ministério da Educação. Secretaria de Educação Básica. Diretoria de Currículos e Educação Integral. Brasília: MEC, SEB, DICEI, 2013.

BRASIL. Programa Mais Educação. Ministério da Educação: Gestão Intersetorial no território. Brasília, Secretaria de Educação Continuada, Alfabetização e Diversidade, 2009.

BRASIL. Ministério da Educação. Caminhos para Elaborar uma Proposta de Educação Integral em Jornada Ampliada. Série Mais Educação. MOLL, Jaqueline Didática e Prática de Ensino na relação com a Sociedade EdUECE - Livro 301799 (org.). CECIP - Centro de Criação de Imagem Popular, Brasília, 2011.

DARDOT, Pierre. LAVAL, Christian. A nova razão do mundo: ensaio sobre a sociedade neoliberal. 1 ed. São Paulo: Boitempo, 2016.

DENZIN, Norman K; LINCOLN, Yvonna Sessions. O planejamento da pesquisa INTERLETRAS, ISSN $N^{\circ}$ 1807-1597. V. 9, Edição número 34. Outubro, 2021/ Março de 2022- p

Dossiê: Educação, infância, diversidade e ensino de língua em contexto complexo. 
qualitativa: teorias e abordagens. Porto Alegre: Artmed, 2006.

FISCHER, Rosa Maria Bueno. O dispositivo pedagógico da mídia: modos de educar na (e pela) TV. Educação e pesquisa. São Paulo. Vol. 28, n. 1 (jan./jun. 2002). p. 151-162, 2002.

FONTE G1. Após corte de 81 mil vagas no ensino integral, Governo de MG anuncia retorno de 34 mil para o $2^{\circ}$ semestre. Belo Horizonte, 26 de jun. 2019, p. 1. Disponível em: encurtador.com.br/eLRW9. Acesso em jun. 2020.

FOUCAULT, Michel. Não ao sexo rei. In: FOUCAULT, Michel. Microfísica do poder. Rio de Janeiro: Ed. Graal, 1979.

O sujeito e o poder. In: DREYFUS, H. L.; RABINOW, P. Michel Foucault: uma trajetória filosófica - para além do estruturalismo e da hermenêutica. Rio de Janeiro: Forense Universitária, 1995.

Microfísica do poder. 26. ed. São Paulo: Graal, 2002a.

Diálogo sobre o poder. In: FOUCAULT, Michel. Estratégia, poder-saber. Rio de Janeiro: Forense Universitária, 2003b. p. 253-266. (Coleção Ditos e Escritos IV).

Vigiar e punir: História da violência nas prisões. São Paulo: Ática, 2004a.

A arqueologia do saber. Tradução de Luiz Felipe Baeta Neves. 4. ed. Rio de Janeiro: Forense Universitária, 2008.

Em defesa da sociedade. Curso dado no Collége de France (1975-1976)/Michel Foucault; Tradução Maria Ermantina Galvão,- 2 ed. São Paulo: Editora WMF Martins Fontes, 2010.

A ordem do discurso: aula inaugural no Collège de France, pronunciada em 2 de dezembro de 1970. Tradução de Laura Fraga de Almeida Sampaio. 22. ed. São Paulo: Edições Loyola, 2014.

GIL, Antonio Carlos. Como elaborar projetos de pesquisa. São Paulo, 2002.

MARCELLO, Fabiana de Amorim. Dispositivo da maternidade: mídia e produção agonística de experiência. 2003.

MOURA, Rodrigo Milhomem de. A des/re/constituição de identidades docentes no dispositivo da educação integral de Goiás. 2020. 166f.Dissertação (Mestrado em Letras e Linguística) - Universidade Federal de Goiás, Goiânia, 2020.

PANIAGO, Maria de Lourdes Faria dos Santos. Práticas discursivas de subjetivação em contexto escolar. 2005. Tese (Doutorado) - Programa de Pós-Graduação em INTERLETRAS, ISSN $N^{\circ}$ 1807-1597. V. 9, Edição número 34. Outubro, 2021/ Março de 2022- p

Dossiê: Educação, infância, diversidade e ensino de língua em contexto complexo. 
Linguística e Língua Portuguesa, Faculdade de Ciências e Letras, Universidade Estadual Paulista, Campus de Araraquara, Araraquara, 2005.

PARAGUASSÚ, Alita Carvalho Miranda. O discurso da desistência do professor: estratégia de resistência e governo de si mesmo. 2017. Tese (Doutorado em Letras e Linguística) - Programa de Pós- Graduação em Letras e Linguística, Faculdade de Letras, Universidade Federal de Goiás, 2017.

PAUZULEZZE, Thaiza. Em PE, ensino integral melhora índices de alunos no ensino superior. (Folha de São Paulo). Pernambuco, 12 de jun. 2019, p.1 Disponível em: https://www1.folha.uol.com.br/educacao/2019/06/em-pe-ensino-integral-melhoraindices-de-alunos-no-ensino-superior.shtml. Acesso em set. 2020.

PRADO FILHO, Kleber et al. Diversidade e diálogo: reflexões sobre alguns métodos de pesquisa em psicologia. In: ZANELLA, Andrea Vieira. Interações, vol. XII, n. 22, p. 1138, jul-dez, 2006.

SARGENTINI, Vanice Maria Oliveira. Dispositivo: um aporte metodológico para estudo do discurso. In: SOUZA, Katia Menezes de Sousa; PAIXÃO, Humberto. Dispositivos e poder em Michel Foucault: biopolítica, corpo e subjetividade. São Paulo: Intermeios, 2015.

SANTAIANA, Rochele da Silva. Educação Integral no Brasil: a emergência do dispositivo de intersetorialidade. 2015. Tese de Doutorado. Tese (Doutorado em Educação). Universidade Federal do Rio Grande do Sul. Faculdade de Educação. Programa de Pós-Graduação em Educação. 2015

SEVERINO, Antonio Joaquim. Metodologia do trabalho científico. Cortez editora, 2007.

TENÓRIO, Aleir Ferraz; SCHELBAUER, Analete Regina. A defesa pela educação integral na obra de Anísio Teixeira. Universidade Estadual de Maringá, Paraná, 2014. p. $01-20$

VEYNE, Paul. Foucault: seu pensamento, sua pessoa. Tradução de Marcelo Jacques de Morais. Rio de Janeiro: Civilização Brasileira, 2014.

\footnotetext{
* Doutorando pelo Programa de Pós- graduação em Letras e Linguística da Universidade Federal de Goiás (UFG) - Goiânia - GO, Brasil. Mestre em Letras e Linguística (UFG). Especialista em Estudos Linguísticos e Literários. Graduado em Língua Portuguesa e suas Respectivas Literaturas pela Universidade do Estado do Pará (UEPA) e graduado em Pedagogia. Participa do Grupo de Pesquisa Portos e do Grupo de Estudos Transdisciplinares e Aplicados à Formação de Educadores (GRUPO PORTOS - UFG/CNPq). ORCID: https://orcid.org/0000-0002-5156-2076.LATTES: http://lattes.cnpq.br/3820645374526854.

**Possui graduação em Letras pela Universidade Federal do Rio Grande do Sul (1994), mestrado em Linguística pela Universidade de Brasília (1999), doutorado em Linguística Aplicada pela Universidade Estadual de Campinas (2007) e pós-doutorado em Linguística pela Universidade de Brasília (2015). É
}

INTERLETRAS, ISSN No 1807-1597. V. 9, Edição número 34. Outubro, 2021/ Março de 2022- p

Dossiê: Educação, infância, diversidade e ensino de língua em contexto complexo. 
professor da Faculdade de Letras da Universidade Federal de Goiás desde 1998, membro de seu Programa e Pós-Graduação em Letras e Linguística e atua na formação de professores. Atualmente, suas pesquisas e orientações concentram-se no reordenamento discursivo da educação no Brasil e na implementação da educação integral no ensino, seus aspectos discursivos, transversais e interdisciplinares. É líder do Grupo de Estudos Transdisciplinares e Aplicados à Formação de Educadores (GRUPO PORTOS - UFG/CNPq). ORCID: https://orcid.org/0000-0003-1243-1927 .LATTES: http://lattes.cnpq.br/4184486812934402 